\title{
The effect of probiotic Escherichia coli strain Nissle 1917 lipopolysaccharide on the 5-aminosalicylic acid transepithelial transport across Caco-2 cell monolayers
}

\author{
Věra Štětinová ${ }^{1}$, Libuše Smetanová ${ }^{1}$, Dagmar Kholová ${ }^{1}$, Jaroslav Květina ${ }^{1}$, Zbyněk Svoboda ${ }^{1}$, \\ Zdeněk Zídek² and Helena Tlaskalová-Hogenová ${ }^{3}$ \\ ${ }^{1}$ Institute of Experimental Biopharmaceutics, Joint Research Centre of PRO.MED.CS Praha a.s. and the Academy \\ of Sciences of the Czech Republic, Hradec Králové, Czech Republic \\ ${ }^{2}$ Institute of Experimental Medicine, v.v.i., Academy of Sciences of the Czech Republic, Prague, Czech Republic \\ ${ }^{3}$ Institute of Microbiology, v.v.i., Academy of Sciences of the Czech Republic, Prague, Czech Republic
}

\begin{abstract}
The object of this study was to investigate the effect of probiotic Escherichia coli strain Nissle 1917 (EcN) (i) EcN lipopolysaccharide (EcN LPS) and (ii) bacteria-free supernatant of EcN suspension (EcN supernatant) on in vitro transepithelial transport of mesalazine (5-aminosalicylic acid, 5-ASA), the most commonly prescribed anti-inflammatory drug in inflammatory bowel disease (IBD).

Effect of co-administered EcN LPS $(100 \mu \mathrm{g} / \mathrm{ml})$ or EcN supernatant $(50 \mu \mathrm{g} / \mathrm{ml})$ on the 5-ASA transport $(300 \mu \mathrm{mol} / \mathrm{l})$ was studied using the Caco-2 monolayer (a human colon carcinoma cell line) as a model of human intestinal absorption. Permeability characteristics for absorptive and secretory transport of parent drug and its intracellularly-formed metabolite were determined. The quantification of 5-ASA and its main metabolite $N$-acetyl-5-amino-salicylic acid ( $N$-Ac-5-ASA) was performed by high performance liquid chromatography.

Obtained results suggest that neither EcN LPS nor EcN supernatant had effect on the total 5ASA transport (secretory flux greater than absorptive flux) and on the transport of intracellularly formed $N$-Ac-5-ASA (preferentially transported in the secretory direction). The percent cumulative transport of the total 5-ASA alone or in combination with EcN LPS or EcN supernatant did not exceed $1 \%$.
\end{abstract}

Key words: Caco-2 cells - Probiotics - E. coli Nissle lipopolysaccharide - 5-Aminosalicylic acid - Drug transport

\begin{abstract}
Abbreviatinos: 5-ASA, 5-aminosalicylic acid; $N$-Ac-5-ASA, $N$-acetyl-5-aminosalicylic acid; AP-BL, apical to basolateral; BL-AP, basolateral to apical; DMEM, Dulbecco's modified Eagle's medium; DPBS, Dulbecco's phosphate buffered salt solution; EcN, probiotic Escherichia coli strain Nissle 1917 O6:K5:H1; EcN LPS, EcN lipopolysacchride; FBS, fetal bovine serum; HBSS, Hanks' balanced salt solution; HEPES, 4-(2-hydroxyethyl)piperazine-1-ethanesulfonic acid; HPLC, high performance liquid chromatography; IBD, inflammatory bowel disease, MES, 2- morpholinoethanesulfonic acid; MRP, multidrug resistance associated proteins; OATP, organic anion transporting polypeptide; $\mathrm{P}_{\mathrm{app}}$, apparent permeability coefficient; UC, ulcerative colitis.
\end{abstract}

Correspondence to: Věra Štětinová, Institute of Experimental Biopharmaceutics, Joint Research Centre of PRO.MED.CS Praha a.s. and the Academy of Sciences of the Czech Republic, Heyrovského 1207, Hradec Králové 500 03, Czech Republic E-mail: stetinovaulmanova@seznam.cz 


\section{Introduction}

Although the observation of the positive role of certain bacteria was firstly introduced at the beginning of the 20th century, an increasing appreciation of the role of probiotics was shown as late as the last decades of the 20th century (Marteau et al. 2002a; Fioramonti et al. 2003). It was shown in vitro (Schultz et al. 2004; Zyrek et al. 2007; Štětinová et al. 2010) and in vivo (Madsen et al. 2001a; Schultz et al. 2004) that probiotics have potential to improve human health, i.e. to prevent and treat a wide variety of diseases (Marteau et al. 2002b; Cukrowska et al. 2002).

However, the most of the identified benefits of probiotics relate to gastrointestinal tract (Madsen et al. 2001a; Marteau et al. 2002b), including antibiotic-associated diarrhoea (Madsen 2001b), acute infectious diarrhoea (Britton and Versalovic 2008), irritable bowel syndrome (Spiller 2008), and inflammatory bowel disease (IBD) (Jones and Foxx-Orenstein 2007). Since the gastrointestinal mucosa is the surface of contact with probiotics, it seems evident that first effects of probiotics relate to digestive function (Fioramonti et al. 2003). Several mechanisms have been proposed to explain the action of probiotics: 1) modulation of barrier function, 2) mucosal trophic action, 3) inhibition of pathogenic bacteria, 4) blockade of epithelial attachment and invasion by pathogenic bacteria, 5) modulation of intestinal cytokine production, 6) antiinflammatory properties, and 7) enhancement of digestion and absorption of food. In most cases, it is likely that more than one mechanism is at work simultaneously (Fioramonti et al. 2003; Jones and Foxx-Orenstein 2007).

In the literature, there is no available information about probiotic effects on transcellular transport of drugs. To study the mechanisms of probiotic effects on the intestinal barrier, cell cultures are regarded as one of the potent tool. And especially the human intestinal epithelial cell line (Caco-2) monolayers (used in our experiments) have been widely accepted as the most useful in vitro model for rapid screening of intestinal drug absorption and drug-drug interactions (Artursson et al. 2001).

Considering mesalazine (5-aminosalicylic acid, 5-ASA) is the most commonly used anti-inflammatory drug in IBD, the possibility of its use in combination with probiotics appears to be evident. Therefore 5-ASA, a drug successfully used for many years in the treatment of IBD (Brogden et al. 1989; Prakash and Markham 1999), has been chosen as a model drug for studying its interaction with probiotics. 5-ASA was shown to be beneficial not only for treatment of IBD - i.e. ulcerative colitis (UC) and Crohn's disease of mild to moderate severity - and for maintaining remission in UC (Brogden et al. 1989; Lichtenstein and Kamm 2008; Actis et al. 2009) but the regular use of 5-ASA was found to be associated with a reduction in the risk of colorectal cancer developing in UC (van Staa et al. 2005; Goel et al. 2009).
In this study, one of the best characterized probiotics, nonpatogenic Escherichia coli strain Nissle 1917 O6:K5:H1 $(\mathrm{EcN})$ exhibiting a serum-sensitive, semirough phenotype (Grozdanov et al. 2002) was used. As for EcN efficacy, there are several clinical trials comparing the oral $\mathrm{EcN}$ and 5-ASA formulations in maintenance of remission of UC. In these trials, EcN showed efficacy and safety equivalent to the gold standard 5-ASA (Kruis et al. 1997, 2004, Rembacken et al. 1999, Faubion 2000). However, in spite of the increasingly recognized role of probiotics, very little is known about drug interactions mediated by probiotics and about changes in efficacy of simultaneously administered drugs. Only paper describing survival of the $\mathrm{EcN}$ in gastrointestinal tract given in combination with oral 5-ASA to healthy volunteers was published (Joeres-Nguyen-Xuan et al. 2010). Authors of this study found no significant effect of 5-ASA on the survival of EcN in healthy volunteers. In contrast to this findings Swidsinski et al. (2007) described a significant reduction of amenability, adherence, and concentrations of mucosal bacteria in the 5-ASA-treated patients with IBD. As drug's fate in the intestinal barrier depends among others on absorption and first pass metabolism, we focused on the study of the effect of EcN bacterial lipopolysaccharide (LPS), a glycolipid of the cell wall of gram-negative bacteria, and EcN bacteria-free supernatant on the 5-ASA intestinal transport (i.e. 5-ASA permeability, transepithelial transport mechanisms of 5-ASA and of its intracellularly formed metabolite $N$-acetyl5 -aminosalicylic acid) using the in vitro model of the human intestinal barrier, Caco-2 cells monolayers.

\section{Materials and Methods}

\section{Materials}

Mesalazine (5-ASA) substance was obtained from PRO. MED.CS, Praha a.s., Czech Republic. Phenol red, 4-(2hydroxyethyl)piperazine-1-ethanesulfonic acid (HEPES), 2-morpholinoethanesulfonic acid (MES), and scintillation liquid (Universal LSC cocktail) were purchased from SigmaAldrich (Czech Republic), propionic anhydride (99\%) and perchloric acid (70\%) from Sigma Aldrich (Germany). Acetonitrile (gradient grade), phosphoric acid (85\%), potassium dihydrogenphosphate $\left(\mathrm{KH}_{2} \mathrm{PO}_{4}\right)$ and methanol (HPLC grade) were from Merck (Germany). Sodium hydrogenphosphate dodecahydrate $\left(\mathrm{Na}_{2} \mathrm{HPO}_{4} \cdot 12 \mathrm{H}_{2} \mathrm{O}\right)$ were obtained from Penta (Czech Republic), sodium hydroxide p.a. from Fluka (Switzerland) and hydrochloric acid (35\%) from LachNer (Czech Republic). The standards ( $N$-propionyl-5-ASA, $\mathrm{N}$-acetyl-5-ASA, internal standard $N$-acetyl-4-ASA) used in HPLC determination, were synthesized in our laboratories. Dulbecco's modified Eagle's medium with high glucose (DMEM), Hanks' balanced salt solution (HBSS) with 
$\mathrm{Ca}^{2+}$, Dulbecco's phosphate buffered salt solution (DPBS), Trypsin-EDTA (1:250), antibiotic-antimycotic solution were obtained from PAA Laboratories (BioTech, Praha, Czech Republic). Fetal bovine serum (FBS) was purchased from Gibco Invitrogen (KRD, Praha, Czech Republic) and ${ }^{14} \mathrm{C}$ mannitol $(100 \mu \mathrm{Ci} / \mathrm{ml})$ from Moravek Radiochemical and Biochemicals (MGP Zlín, Czech Republic).

\section{Isolation of EcN lipopolysaccharide (EcN LPS)}

EcN LPS was isolated by the phenol-water extraction from the Escherichia coli Nissle 1917 O6:K5:H1 (Zídek et al. 2010).

\section{Preparation of EcN supernatant}

$\mathrm{EcN}$ supernatant was obtained after the third washing of EcN suspension in RPMI-1640 medium (Zídek et al. 2010). Both EcN LPS and EcN supernatant were prepared at the Institute of Microbiology, Academy of Sciences of the Czech Republic.

\section{Cell culture}

The Caco-2 cell line was purchased from the European collection of cell culture (Sigma-Aldrich, Czech Republic) and used between passages 71 and 79 . The cells were routinely grown (Bourdet and Thakker 2006, Štětinová et al. 2009) in plastic tissue culture flasks $\left(75 \mathrm{~cm}^{2}\right.$ growth area, TPP AG, Switzerland) in DMEM containing $25 \mathrm{mmol} / \mathrm{l}$ glucose and supplemented with $4 \mathrm{mmol} / \mathrm{l} \mathrm{L}$-glutamine, 10\% FBS, 1\% nonessential amino acids, $100 \mathrm{U} / \mathrm{ml}$ penicillin, $100 \mu \mathrm{g} / \mathrm{ml}$ streptomycin, and $0.25 \mu \mathrm{g}$ amphotericin. Cell line was cultured at $37^{\circ} \mathrm{C}$ in an atmosphere of $5 \% \mathrm{CO}_{2}$ and $90 \%$ relative humidity, and passaged at about $90 \%$ confluence, using $0.05 \%$ trypsin (1:250) - $0.02 \%$ EDTA in calcium-free and magnesium-free phosphate-buffered saline (DPBS). The medium was changed three times a week.

For 5-ASA transport experiments, the cells were seeded onto polycarbonate filter cell culture chamber inserts (dimensions $\varnothing 13 \times 11 \mathrm{~mm}$, area available for growth $0.5 \mathrm{~cm}^{2}$, pore diameter $0.4 \mu \mathrm{m}$ ) of tissue culture plates containing 24 wells (TPP AG, Switzerland) at the density of $2.5 \times 10^{5}$ cells $/ \mathrm{cm}^{2}$. Caco-2 cells were used for transport experiments 21-25 days post-seeding (Štětinova et al. 2009). Before experiments, the integrity of the monolayer was checked by 500 $\mu \mathrm{mol} / \mathrm{ml}$ phenol red permeability and during experiments simultaneously by measuring ${ }^{14} \mathrm{C}$ mannitol $(0.5 \mu \mathrm{Ci} / \mathrm{ml})$ permeability (Briske-Anderson et al. 1997, Smetanová et al. 2008). The apparent permeability coefficient $\left(\mathrm{P}_{\text {app }}\right)$ of ${ }^{14} \mathrm{C}$ mannitol was $1.49 \pm 0.29 \times 10^{-6} \mathrm{~cm} / \mathrm{s}$. There was no effect of EcN LPS $(100 \mu \mathrm{g} / \mathrm{ml})$ or EcN supernatant $(50 \mu \mathrm{g} / \mathrm{ml})$ on the $\mathrm{P}_{\text {app }}$ of ${ }^{14} \mathrm{C}$ mannitol (Štětinová et al. 2010).

\section{Transport studies}

Transport experiments were performed with transport medium (Ingels and Augustijns 2003) - Hanks' balanced salt solution (HBSS) buffered with $25 \mathrm{mmol} / \mathrm{l}$ HEPES ( $\mathrm{pH}$ 7.4). The prepared Caco-2 cell inserts were rinsed twice with prewarm $\mathrm{HBSS}$ and equilibrated with $\mathrm{HBSS}$ at $37^{\circ} \mathrm{C}$ for $30 \mathrm{~min}$ before the transport experiments (Walle and Walle 1998).

The transport experiments from apical to basolateral side (AP-BL) were initiated by replacing the transport medium with 5-ASA alone $(300 \mu \mathrm{mol} / \mathrm{l})$ or in combination with either EcN LPS $(100 \mu \mathrm{g} / \mathrm{ml})$ or EcN supernatant $(50 \mu \mathrm{g} / \mathrm{ml})$ in the transport medium $(500 \mu \mathrm{l})$ on the apical side. The samples of $500 \mu \mathrm{l}$ from the basolateral compartment were withdrawn at 30, 60, 90 and $120 \mathrm{~min}$ for HPLC analysis and the same volume of the prewarmed transport medium was added to the basolateral compartment. During withdrawing samples the 24-transwell plate was placed on a heated plate $\left(37^{\circ} \mathrm{C}\right)$. Between sampling, the cells were kept in an incubator at $37^{\circ} \mathrm{C}$ and $5 \% \mathrm{CO}_{2}$.

Similarly, for BL-AP (basolateral to apical) transport, the drug (5-ASA alone or in combination) was added to the basolateral compartment $(650 \mu \mathrm{l})$ and the volume of $300 \mu \mathrm{l}$ was withdrawn from the receiver side in the same time intervals.

All used solutions and transport media were sterile filtered just before the experiments. All experiments were carried out under sink conditions so that the concentrations of the drug in the receiver compartment would not exceed $10 \%$ of the applied dose in the donor side and under iso-pH conditions ( $\mathrm{pH} 7.4$ in both sides).

\section{HPLC analysis of 5-ASA}

The quantification of 5-ASA was performed by high performance liquid chromatography (HPLC) with gradient elution. A modified method of Nobilis et al. (2006) was used. Withdrawn samples of 5-ASA in the transport medium were analyzed for 5-ASA and $\mathrm{N}$-acetyl-5-aminosalicylic acid ( $N$ Ac-5-ASA). Chromatographic separation was performed on the analytical column $\mathrm{N}$-acetyl-5-aminosalicylic acid $\mathrm{n}$ LichroCART $^{\circledast}(250 \times 4 \mathrm{~mm})$ packed with Purospher RP18e $5 \mu \mathrm{m}$ and precolumn LiChroCART ${ }^{\oplus} 4-4$ with the same stationary phase (Merck, Darmstadt, Germany). The mobile phase A consisted of an acetonitrile - UHQ water $(8: 2, \mathrm{v} / \mathrm{v})$, the mobile phase $\mathrm{B}$ contained acetonitrile- $0.01 \mathrm{M} \mathrm{Na}_{2} \mathrm{HPO}_{4}$ buffer ( $\mathrm{pH} 3)$ in the ratio 15:85 (v/v). The flow-rate was $1 \mathrm{ml} /$ min and elution of 5-ASA and N-Ac-5-ASA was monitored at a fluorescence excitation wavelength of $300 \mathrm{~nm}$ and an emission wavelength of $406 \mathrm{~nm}$, the total run was $21 \mathrm{~min}$ for each sample. The quantitative determination was based upon the integration of fluorescence peak area. 


\section{Data analysis}

Calculation of $P_{a p p}(\mathrm{~cm} / \mathrm{s})$ of the total 5-ASA (5-ASA + N-Ac5-ASA)

$\mathrm{P}_{\text {app }}$ was calculated according to the equation: $\mathrm{P}_{\mathrm{app}}=(\mathrm{dQ} /$ $\mathrm{d} t) \times\left(1 /\left(\mathrm{A} \times \mathrm{C}_{0}\right)\right)$, where $\mathrm{d} Q / \mathrm{d} t$ is the permeability rate, the amount of drug appearing in the receiver compartment in function of time $(\mathrm{nmol} / \mathrm{s}), \mathrm{C}_{0}$ is the initial concentration in the donor chamber $(\mathrm{nmol} / \mathrm{ml})$, and $\mathrm{A}$ is the surface area of the monolayer $\left(\mathrm{cm}^{2}\right)$ (Artursson and Karlsson 1991).

\section{Evaluation of the bidirectional flux}

Transport in both directions across monolayer enables to calculate an efflux ratio (Ungell and Karlsson 2004):

$$
\mathrm{P}_{\mathrm{app}} \text { efflux ratio }=\mathrm{P}_{\mathrm{app}} \mathrm{BL}-\mathrm{AP} / \mathrm{P}_{\mathrm{app}} \mathrm{AP}-\mathrm{BL}
$$

\section{Cumulative transport of the total 5-ASA}

Calculated total cumulative amount of 5-ASA (5-ASA + $\mathrm{N}$-Ac-5-ASA; nmol) estimated in received chamber were plotted versus time.

\section{Percent transport}

Percent transport was calculated for each time interval as the ratio of the cumulative concentration of the total 5-ASA (5ASA + N-Ac-5-ASA) or 5-ASA and N-Ac-5-ASA, separately, in the receiver chamber to the concentration in the donor chamber $\times 100$.

A

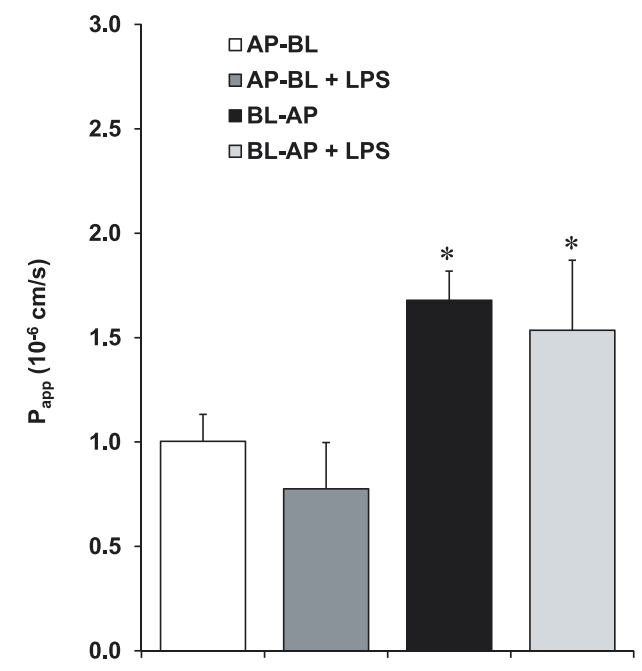

Statistical analysis

All values are represented as mean \pm standard deviation $(\mathrm{SD})$ of four to six experiments. Statistical differences were determined using Kruskal-Wallis one way analysis of variance (ANOVA) followed by Tukey's post hoc test. The differences were considered significant when $p<0.05$. In figures only significant differences are marked and described in detail in the legend.

\section{Results}

Calculation of $P_{\mathrm{app}}$ of the total 5-ASA (5-ASA + N-Ac5-ASA)

\section{Effect of EcN LPS}

The $\mathrm{P}_{\text {app }}$ of 5-ASA showed that the secretory flux (BL-AP) was significantly greater than absorptive flux (AP-BL). The calculated $\mathrm{P}_{\text {app }}$ efflux ratio was 1.68. EcN LPS slightly lowered (nonsignificantly) $\mathrm{P}_{\mathrm{app}} \mathrm{s}$ of 5-ASA in both directions, the efflux ratio in the presence of EcN LPS was 1.96 (Fig. 1A).

\section{Effect of EcN supernatant}

Similarly as in the case of EcN LPS, the asymmetric transport of 5-ASA was not influenced by EcN supernatant; EcN supernatant slightly (nonsignificantly) increased the $\mathrm{P}_{\text {app }}$ values in both directions (Fig. 1B) and the $\mathrm{P}_{\text {app }}$ efflux ratios for 5-ASA transport and for transport of 5-ASA in combination with EcN supernatant were 1.86 and 1.87 , respectively.

B

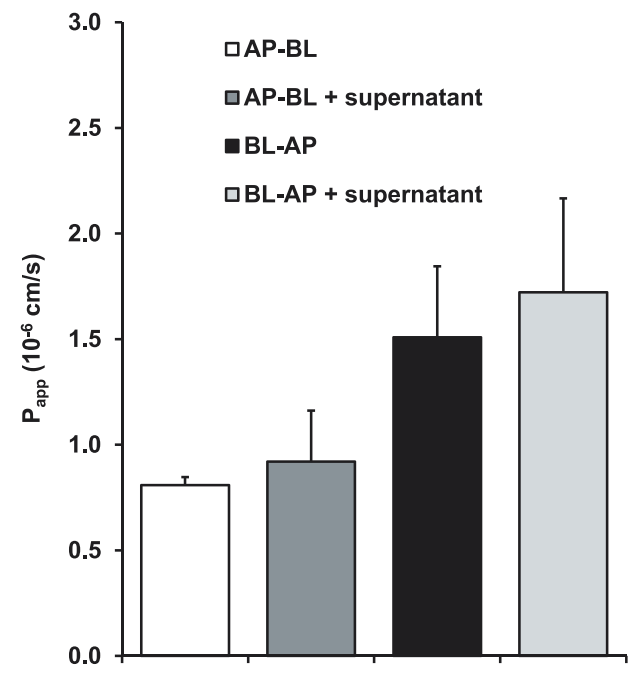

Figure 1. Bidirectional transport (AP-BL and BL-AP) of the total 5-ASA across Caco-2 monolayer in the absence or in the presence of EcN LPS (A) or EcN supernatant $(\mathbf{B})$. Data represent the mean \pm SD of the permeability coefficient $\left(\mathrm{P}_{\text {app }}\right),(n=4-6)$, ${ }^{*}$ significant differences between AP-BL and BL-AP directions $(p<0.05)$. 
Cumulative transport of the total 5-ASA (5-ASA + N-Ac5-ASA)

\section{Effect of EcN LPS}

The cumulative BL-AP transport of 5-ASA (nmol) and 5ASA in combination with EcN LPS seems to be linear up to $2 \mathrm{~h}$. The cumulative AP-BL transport of 5-ASA and 5-ASA in combination with EcN LPS were linear up to $90 \mathrm{~min}$ and the amount of 5-ASA and 5-ASA in combination with $\mathrm{EcN}$ transported in the last time interval (Fig. 2A) was lower than the amount transported in each previous interval.

\section{Effect of EcN supernatant}

The cumulative bidirectional transport of 5-ASA (nmol) and 5-ASA with EcN supernatant were roughly linear up to $120 \mathrm{~min}$, except the BL-AP transport of 5-ASA with EcN supernatant that demonstrated higher transport in the last time interval (Fig. 2B).
A

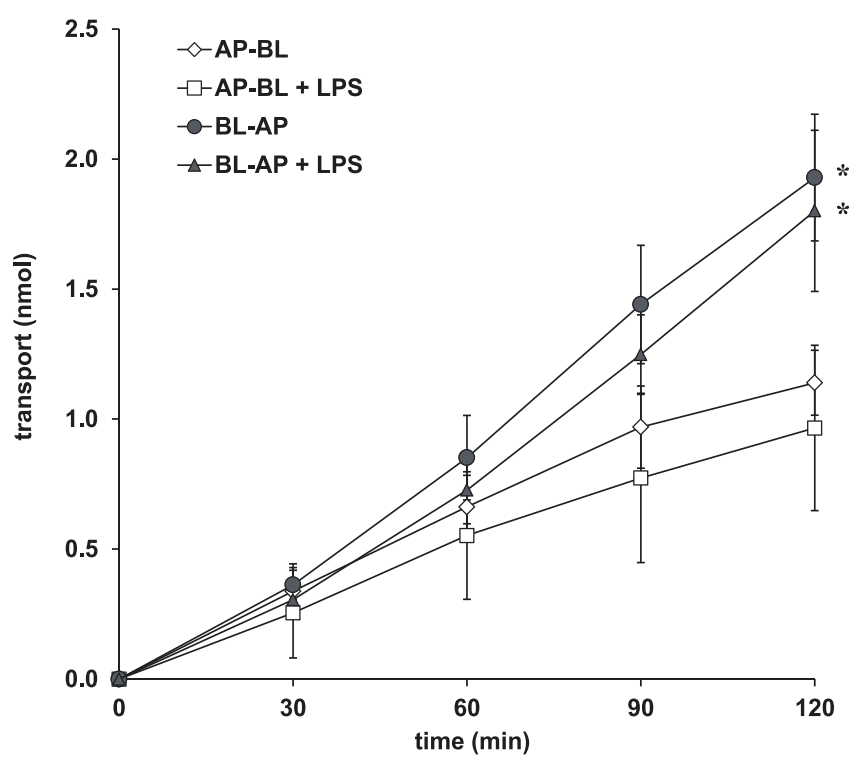

B

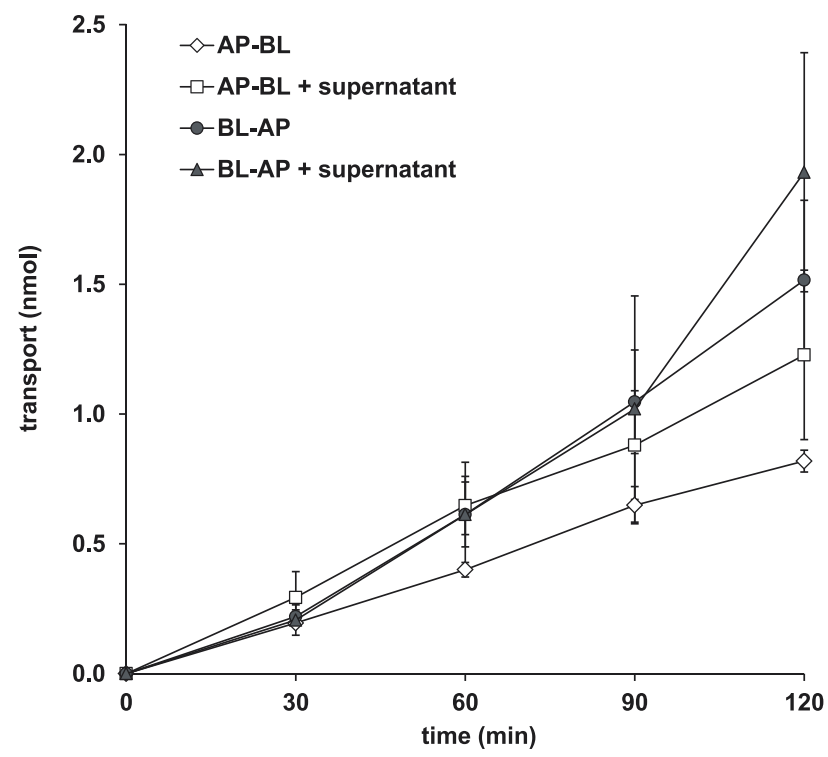

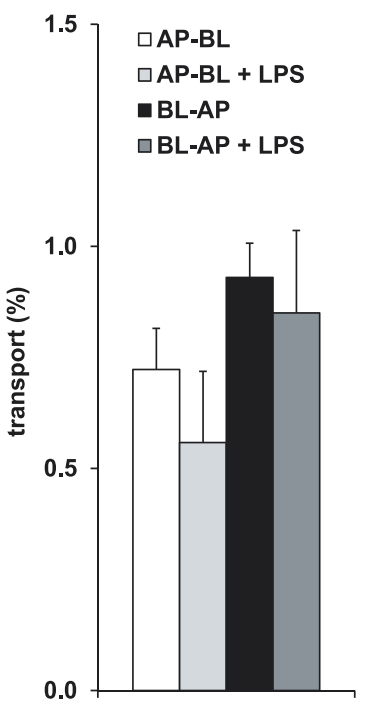

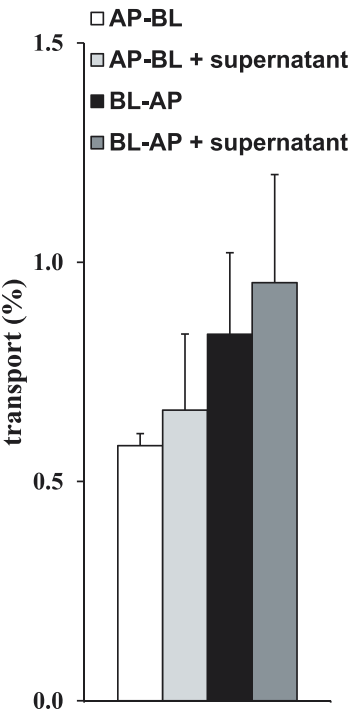

Figure 2. Cumulative bidirectional transport of the total 5-ASA across Caco-2 monolayer (nmol) and the percent cumulative bidirectional transport at $120 \mathrm{~min}$ in the absence and in the presence of EcN LPS (A) or EcN supernatant (B). Data represent the mean $\pm \operatorname{SD}(n=4-6)$, ${ }^{*}$ significant differences between AP-BL and BL-AP directions $(p<0.05)$. 


\section{Percent transport of the total 5-ASA (5-ASA + N-Ac-5-ASA)}

The percent transport of the total 5-ASA and 5-ASA in combination with EcN LPS or EcN supernatant did not exceed $1 \%$.

\section{Effect of EcN LPS}

The percent cumulative transport estimated at each time interval showed that the percent transport was greater in BL-AP direction than in AP-BL for both 5-ASA and 5-ASA with EcN LPS (only values at $120 \mathrm{~min}$ are presented, Fig. 2A). EcN LPS slightly lowered transport of 5-ASA in both directions.

\section{Effect of EcN supernatant}

The percent cumulative BL-AP transport of 5-ASA was higher in comparison with AP-BL direction. As for effect of EcN supernatant (Fig. 2B), data from the last time interval (120 min) showed slightly increased percent transport of 5-ASA in both direction.

\section{Percent transport of parent 5-ASA and intracellularly formed metabolite N-Ac-5-ASA}

\section{Effect of EcN LPS}

The bidirectional transport of 5-ASA expressed as (i) percentage cumulative amount of parent drug (5-ASA) and as (ii) percentage cumulative amount of its main metabolite ( $N$-Ac-5-ASA) estimated in receiver sides and the effect of EcN LPS is shown in Fig. 3. The AP-BL transport of the produced $\mathrm{N}$-Ac-5-ASA was minimal in comparison with metabolite flux in BL-AP direction at each time interval (data not shown). At $120 \mathrm{~min}$ the absorptive metabolite flux was significantly lower (at mean 6.6-times). The EcN LPS slightly (nonsignificantly) decreased the percent transport of the parent 5-ASA and its metabolite in each time interval in both directions (data not shown). At $120 \mathrm{~min}$, the percent transport of the parent drug was decreased 1.3-times in AP$\mathrm{BL}$ direction and was almost the same in BL-AP direction. The percent transport of $\mathrm{N}$-Ac-5-ASA was lowered 1.2-times in AP-BL direction and was the same in BL-AP direction in comparison with 5-ASA transport (Fig. 3).

\section{Effect of EcN supernatant}

Up to 90 min the transport of 5-ASA (parent drug) and its metabolite were almost the same after coadministration with EcN supernatant (data not shown). Only at 120 min (Fig. 4) nonsignificantly higher transport of parent drug in BL-AP direction (1.36-times) and transport of metabolite in AP-BL direction (1.5-times) was observed after coadministration of $\mathrm{EcN}$ supernatant in comparison with values reached after administration of 5-ASA alone.

\section{Discussion}

With the increasing interest in probiotics exerting preventive or therapeutic effects in several experimental models and clinical studies, their interactions with medications cannot be excluded even though interactions with medications or other supplements are not known so far (Kligler and Cohrssen 2008).

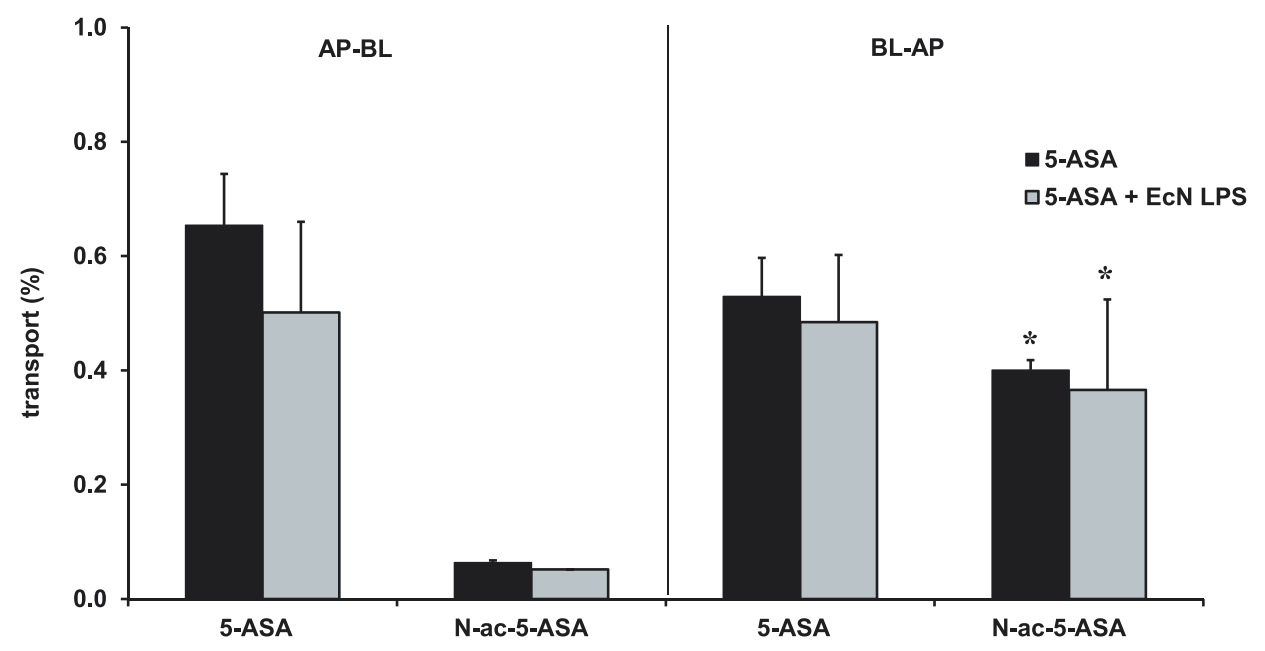

Figure 3. Effect of EcN LPS on 5-ASA $(300 \mu \mathrm{mol} / \mathrm{l})$ percent cumulative transport (5-ASA and intracellularly formed $N$-ac-5-ASA, separately) at $120 \mathrm{~min}$. Data represent the mean $\pm \mathrm{SD}(n=4-6) .{ }^{*}$ significant differences between AP-BL and BL-AP directions $(p<0.05)$. 


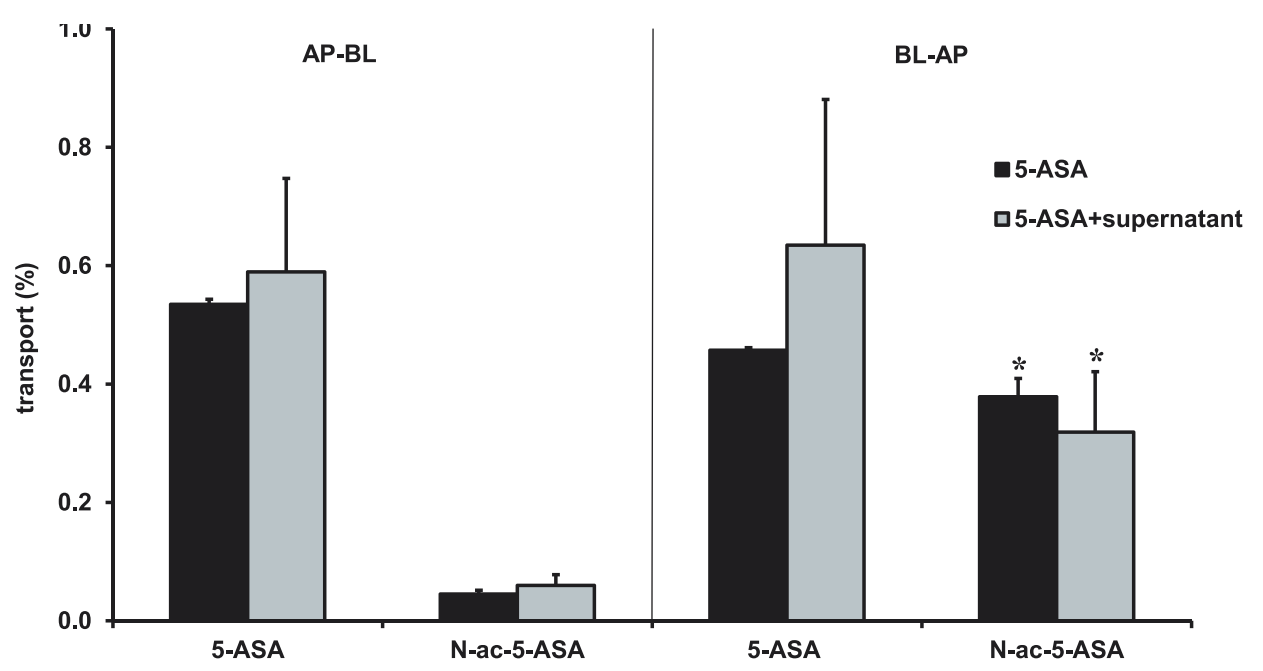

Figure 4. Effect of EcN supernatant on 5-ASA $(300 \mu \mathrm{mol} / \mathrm{l})$ percent cumulative transport (5-ASA and intracellularly formed $N$-ac-5ASA, separately) at $120 \mathrm{~min}$. Data represent the mean $\pm \mathrm{SD}(n=4-6) .{ }^{*}$ significant differences between AP-BL and BL-AP directions $(p<0.05)$.

As recent knowledge indicates efficacy of probiotics in IBD, we focused on the interaction of EcN components with 5-ASA (effective agent for the treatment of IBD). To evaluate the transport of 5-ASA alone or in combination with EcN LPS $100 \mu \mathrm{g} / \mathrm{ml}$ or EcN supernatant $50 \mu \mathrm{g} / \mathrm{ml}$, the Caco-2 permeability model was used as an in vitro tool to predict absorption in man (Ungell and Karlsson 2004). In many respects Caco- 2 cells are functionally similar to the human small intestinal enterocyte, despite the fact that they originate from a human colorectal carcinoma (Artursson and Tavelin 2004). Evaluation of the drug intestinal permeability is essential as the rate and extent of drug absorption and metabolic enzymes activity are the most important factors determining total drug bioavailability.

We have described earlier (Štětinová et al. 2011) that the transport of 5-ASA is asymmetric in Caco-2 cells, 5-ASA $\mathrm{BL}-\mathrm{AP}$ transport being higher than AP-BL direction. In the present study we have shown that the transport of 5-ASA was unchanged by EcN LPS or EcN supernatant. At given conditions EcN LPS slightly lowered 5-ASA transport in both directions, whereas EcN supernatant slightly increased the bidirectional transport of 5-ASA (cumulative transport (nmol), percent transport at $120 \mathrm{~min}$ and $\mathrm{P}_{\mathrm{app}}$ values of 5-ASA). However, these changes were not significant and seem to be accidental caused only by biological fluctuation. These insignificant changes in 5-ASA transport induced by EcN LPS or EcN supernatant are in accordance with the fact that neither the high concentration of LPS $(1000 \mu \mathrm{g} / \mathrm{ml})$ have significant effect on the viability of Caco-2 cells nor the concentrations of EcN LPS $(1000,100 \mu \mathrm{g} / \mathrm{ml})$ and $\mathrm{EcN}$ supernatant $(50 \mu \mathrm{g} / \mathrm{ml})$ revealed effect on the tightness of cell junctions, as it has been recently estimated by testing the integrity of Caco-2 monolayer using ${ }^{14} \mathrm{C}$ mannitol as marker of paracellular transport across Caco-2 monolayer (Štětinová et al. 2010). Thus, we can conclude that neither EcN LPS nor $\mathrm{EcN}$ supernatant has effect on the 5-ASA transport.

It is believed that asymmetric transport of 5-ASA at low concentration (preferentially transported in the basolateral to apical direction) indicates presence of carrier-mediated saturable transepithelial transport. Our results showed in concordance with Zhou et al. (1999a) that this asymmetric transport of total 5-ASA is due to a strictly secretory transport of N-Ac-5-ASA. Several authors investigated which efflux pumps on the apical membrane are involved in $\mathrm{N}$-Ac-5-ASA efflux. Xin et al. (2006) demonstrated that 5-ASA is not a substrate of P-glycoprotein, Yoshimura et al. (2009) deduced that this metabolite is pumped out by an MRPs-like transporter. Futhermore, it has been shown recently that intracellular accumulation of 5-ASA is mediated by members of the OATP uptake transporter family (OATP1B1, OATP1B3, and OATP2B1), which are expressed in small and large intestine (Köning et al. 2011) and also in Caco- 2 cells (Englund et al. 2006, Seithel et al. 2006, Maubon et al. 2007). According to published data (Köning et al. 2011) 5-ASA OATP- mediated uptake may be modified by genetic factors and by comedication.

Showing no changes in transport of intracellularly formed main metabolite $\mathrm{N}$-Ac-5-ASA it can be indirectly supposed that neither EcN LPS nor EcN supernatant had effect on the $\mathrm{N}$-acetyltransferase 1 activity and on the metabolite transport. Both these factors has to be kept in view even though the direct effects of probiotics on transporters function and on their expression are not extensively elucidated; e.g., Saksena et al. (2010) cited stimulation effect of probiotics 
(Lactobacilli or their soluble factors) on P-glycoprotein expression in Caco-2 cells and in in vivo in MDR1-deficient mice. It can be generally supposed that the fate of intracellularly formed metabolite depends on the current state of both actions - inhibition versus stimulation of transporters expression and $N$-acetyltransferase 1 activity.

These transport experiments indirectly showed no factors or mechanisms (e.g., effect on transporters, on enzyme activity) which would be able to magnify the 5-ASA effect and evoke synergistic effect of concomitant administration of 5-ASA plus EcN LPS or EcN supernatant. On the other hand, neither EcN LPS nor EcN supernatant has harmful effect on 5-ASA transport in in vitro conditions.

In summary, higher secretory than absorptive flux of the total 5-ASA (parent drug plus metabolite) and preferential secretory flux of intracellularly produced 5-ASA metabolite (N-Ac-5-ASA) were not significantly changed by concomitant administration of EcN LPS or EcN supernatant.

Acknowledgements The authors wish to thank Ms Hana Machova for her skilful technical assistance. The study was supported by the research projects GAČR No. 305/08/0535 and No. P304/11/1252.

\section{References}

Actis G. C., Pellicano R., Rizzetto M., Ayoubi M., Leone N., Tappero G., Pazienza P., Rosina F. (2009): Individually administered or co-prescribed thiopurines and mesalamines for inflammatory bowel disease. World J. Gastroenterol. 15, 1420-1426 http://dx.doi.org/10.3748/wjg.15.1420

Artursson P., Karlsson J. (1991): Correlation between oral drug absorption in humans and apparent drug permeability coefficients in human intestinal epithelial (Caco-2) cells. Biochem. Biophys. Res. Commun. 175, 880-885 http://dx.doi.org/10.1016/0006-291X(91)91647-U

Artursson P., Palm K., Luthman K. (2001): Caco-2 monolayers in experimental and theoretical predictions of drug transport. Adv. Drug Deliv. Rev. 46, 27-43

http://dx.doi.org/10.1016/S0169-409X(00)00128-9

Artursson P., Tavelin S. (2004): Caco-2 and emerging alternatives for prediction of intestinal drug transport: a general overview. In: Drug Bioavailability. (Eds. H. Waterbeemd, H. Lennernäs and P. Artursson), pp. 72-89, (2nd edition), Wiley-Vch. Verlag GmbH\&Co. KGaA, Weinheim

Bourdet D. L., Thakker D. R. (2006): Saturable absorptive transport of the hydrophilic organic cation ranitidine in Caco-2 cells: role of $\mathrm{pH}$-dependent organic cation uptake system and Pglycoprotein. Pharm. Res. 23, 1165-1177 http://dx.doi.org/10.1007/s11095-006-0251-4

Briske-Anderson M. J., Finley J. W., Newman S. M. (1997): The influence of culture time and passage number on the morphological and physiological development of Caco-2 cells. Proc. Soc. Exp. Biol. Med. 214, 248-257 http://dx.doi.org/10.3181/00379727-214-44093
Britton R. A., Versalovic J. (2008): Probiotics and gastrointestinal infections. Interdiscip. Perspect. Infect. Dis. 290769 http://dx.doi.org/10.1155/2008/290769

Brogden R. N., Sorkin E. M., Mesalazine (1989): A review of its pharmacodynamic and pharmacokinetic properties, and therapeutic potential in chronic inflammatory bowel disease. Drugs 38, 500-523

http://dx.doi.org/10.2165/00003495-198938040-00003

Cukrowska B., Lodínová-Žádniková R., Enders C., Sonnenborn U., Schulze J., Tlaskalová-Hogenová H. (2002): Specific proliferative and antibody responses of premature infants to intestinal colonization with nonpathogenic probiotic E. coli strain Nissle 1917. Scand. J. Immunol. 55, 204-209 http://dx.doi.org/10.1046/j.1365-3083.2002.01005.x

Englund G., Rorsman F., Rönnblom A., Karlbom U., Lazorova L., Gråsjö J., Kindmark A., Artursson P. (2006): Regional levels of drug transporters along the human intestinal tract: Co-expression of ABC and SLC transporters and comparison with Caco-2 cells. Eur. J. Pharm. Sci. 29, 269-277 http://dx.doi.org/10.1016/j.ejps.2006.04.010

Faubion W. A. (2000): Probiotic therapy with E. coli for ulcerative colitis: take the good with the bad. Gastroenterology 118, 630-635 http://dx.doi.org/10.1016/S0016-5085(00)70272-1

Fioramonti J., Theodorou V., Bueno L. (2003): Probiotics: What are they? What are their effects on gut physiology? Best Prac. Res. Clin. Gastroenterol. 17, 711-724 http://dx.doi.org/10.1016/S1521-6918(03)00075-1

Goel A., Mittal A., Evstatiev R. Nemeth M., Kruis W., Stolte M., Boland C. R., Gasche C. (2009): In vivo effects of mesalazine or E. coli Nissle 1917 on microsaellite instability in ulcerative colitis. Aliment. Pharmacol. Ther. 30, 634-642 http://dx.doi.org/10.1111/j.1365-2036.2009.04076.x

Grozdanov L., Zähringer U., Blum-Oehler G. Brade L., Henne A., Knirel Y. A., Schombel U., Schulze J., Sonnenborn U., Gottschalk G., Hacker J., Rietschel E. T., Dobrindt U. (2002): A single nucleotide exchange in the wzy gene is responsible for the semirough O6 lipopolysaccharide phenotype and serum sensitivity of Escherichia coli strain Nissle 1917. J. Bacteriol. 184, 5912-5922 http://dx.doi.org/10.1128/JB.184.21.5912-5925.2002

Ingels F. M., Augustijns P. F. (2003): Biological, pharmaceutical, and analytical considerations with respect to the transport media used in the absorption screening system, Caco-2. J. Pharmac. Sci. 92, 1545-1558 http://dx.doi.org/10.1002/jps.10408

Joeres-Nguyen-Xuan T. H., Boehm S. K., Joeres L., Schulze J., Kruis W. (2010): Survival of the probiotic Escherichia coli Nissle $1917(\mathrm{EcN})$ in the gastrointestinal tract given in combination with oral mesalamine to healthy volunteers. Inflamm. Bowel Dis. 16, 256-262 http://dx.doi.org/10.1002/ibd.21042

Jones J. L., Foxx-Orenstein A. E. (2007): The role of probiotics in inflammatory bowel disease. Dig. Dis. Sci. 52, 607-611 http://dx.doi.org/10.1007/s10620-006-9225-y

Kligler B., Cohrssen A. (2008): Probiotics. Am. Fam. Physician. 78, 1073-1078

Köning J., Glaeser H., Keiser M., Mandery K., Klotz U., Fromm M. F. (2011): Role of organic anion-transporting polypeptides 
for cellular mesalazine (5-aminosalicylic acid) uptake. Drug Metab. Dispos. 39, 1097-1102

http://dx.doi.org/10.1124/dmd.110.034991

Kruis W., Schütz E., Fric P., Fixa B., Judmaier G., Stolte M. (1997): Double-blind comparison of an oral Escherichia coli preparation and mesalazine in maintaining remission of ulcerative colitis. Aliment. Pharmacol. Ther. 11, 853-858 http://dx.doi.org/10.1046/j.1365-2036.1997.00225.x

Kruis W., Frič P., Pokrotnieks J. Lukáš M., Fixa B., Kaščák M., Kamm M. A., Weismueller J., Beglinger C., Stolte M., Wolff C., Schulze J. (2004): Maintainig remission of ulcerative colitis with the probiotic Escherichia coli Nissle 1917 is as effective as with standard mesalazine. Gut 53, 1617-1623

http://dx.doi.org/10.1136/gut.2003.037747

Lichtenstein G. R., Kamm M. A. (2008): Review article: 5-aminosalicylate formulations for the treatment of ulcerative colitis - methods of comparing release rates and delivery of 5-aminosalicylate to the colonic mucosa. Aliment. Pharmacol. Ther. 28, 663-673 http://dx.doi.org/10.1111/j.1365-2036.2008.03751.x

Madsen K., Cornish A., Soper P., Mckaigney C. Jijon H., Yachimec Ch., Doyle J., Jewell L., De Simone C. (2001a): Probiotic bacteria enhance murine and human intestinal epithelial barrier function. Gastroenterology 121, 580-591 http://dx.doi.org/10.1053/gast.2001.27224

Madsen K. L. (2001b): The use of probiotics in gastrointestinal disease. Can. J. Gastroenterol. 15, 817-822

Marteau P., Cuillerier E., Meance S. Gerhardt M. F., Myara A., Bouvier M., Bouley C., Tondu F., Bommelaer G., Grimaud J. C. (2002a): Bifidobacterium animalis strain DN-173010 shortens the colonic transit time in healthy women: a doubleblind, randomized, controlled study. Aliment. Pharmacol. Ther. 16, 587-593 http://dx.doi.org/10.1046/j.1365-2036.2002.01188.x

Marteau P., Seksik P., Jian R. (2002b): Probiotics and health: new facts and ideas. Curr. Opin. Biotechnol. 13, 486-489 http://dx.doi.org/10.1016/S0958-1669(02)00368-3

Maubon N., Le Vee M., Fossati L., Audry M., Le Ferrec E., Bolze S., Fardel O. (2007): Analysis of drug transporter expression in human intestinal Caco-2 cells by real-time PCR. Fund. Clin. Pharmacol. 21, 659-663 http://dx.doi.org/10.1111/j.1472-8206.2007.00550.x

Nobilis M., Vybíralová Z., Sládková K., Lísa M., Holčapek M., Květina J. (2006): High-performance liquid-chromatographic determination of 5-aminosalicylic acid and its metabolites in blood plasma. J. Chromatogr. A 1119, 299-308 http://dx.doi.org/10.1016/j.chroma.2006.01.058

Prakash A., Markham A. (1999): Oral delayed-release mesalazine: a review of its use in ulcerative colitis and Crohn's disease. Drugs 57, 383-408 http://dx.doi.org/10.2165/00003495-199957030-00013

Rembacken B. J., Snelling A. M., Hawkey P. M., Chalmers D. M., Axon A. T. R. (1999): Non-pathogenic Escherichia coli versus mesalazine for the treatment of ulcerative colitis: a randomised trial. Lancet 354, 635-639

http://dx.doi.org/10.1016/S0140-6736(98)06343-0

Saksena S., Raheja G., Singh V., Goyal S., Anbazhagan A. N., Gill R. K., Alrefai W. A., Dudeja P. K. (2010): Probiotics stimulace
P-glycoprotein exspression in intestina epithelial cells. Gastroenterology 138 (Suppl.1), S746 http://dx.doi.org/10.1016/S0016-5085(10)63439-7

Schultz M., Strauch U. G., Linde H.-J., Watzl S., Obermeier F., Göttl C., Dunger N., Grunwald N., Schölmerich J., Rath H. C. (2004): Preventive effects of Escherichia coli strain Nissle 1917 on acute and chronic intestinal inflammation in two different murine models of colitis. Clin. Diagn. Lab. Immunol. 11, 372-378

Seithel A., Karlsson J., Hilgendorf C. Björquist A., Ungell A. L. (2006): Variability in mRNA expression of ABC- and SLCtransporters in human intestinal cells: Comparison between human segments and Caco-2 cells. Eur. J. Pharm. Sci. 28, 291-298 http://dx.doi.org/10.1016/j.ejps.2006.03.003

Smetanova L., Stetinova V., Kvetina J., Svoboda Z. (2008): The use of 14C-mannitol and phenol red in the assessment of the Caco-2 monolayer integrity. Prague Med. Rep. 109 (Suppl.), S109-111

Spiller R. (2008): Review article: probiotics and prebiotics in irritable bowel syndrome. Aliment. Pharmacol. Ther. 28, 385-396 http://dx.doi.org/10.1111/j.1365-2036.2008.03750.x

Swidsinski A., Loening-Baucke V., Bengmark S., Lochs H., Dörffel Y. (2007) Azathioprine and mesalazine-induced effects on the mucosal flora in patiens with IBD colitis. Inflamm. Bowel Dis. 13, 51-56 http://dx.doi.org/10.1002/ibd.20003

Štětinová V., Smetanová L., Kholová D., Svoboda Z., Květina J. (2009): Transepithelial transport of ambroxol hydrochloride across human intestinal Caco-2 cell monolayers. Gen. Physiol. Biophys. 28, 309-315

http://dx.doi.org/10.4149/gpb_2009_03_309

Štětinová V., Smetanová L., Květina J., Svoboda Z., Zídek Z., Tlaskalová-Hogenová H. (2010): Caco-2 cell monolayer integrity and effect of probiotic Escherichia coli Nissle 1917 components. Neuroendocrinol. Lett. 31 (Suppl. 2), 51-56

Štětinová V., Smetanová L., Kholová D., Květina J., Svoboda Z. (2011): Transepithelial transport of 5-aminosalicylic acid (5ASA) across human intestinal Caco-2 cell monolayers. Book of Abstracts, p.142, (Czech-Slovak 61st Pharmacological days, Brno, 14.-16. 9. 2011)

Ungell A.-L., Karlsson J. (2004): Cell culture in drug discovery: an industrial perspective. In: Drug Bioavailability. (Eds. H. Waterbeemd, H. Lennernäs and P. Artursson), pp. 90-131, (2nd edition), Wiley-Vch. Verlag GmbH\&Co. KGaA, Weinheim

van Staa T. P., Card T., Logan R. F., Leufkens H. G. M. (2005): 5-Aminosalicylate use and colorectal cancer risk in inflammatory bowel disease: a large epidemiological study. Gut 54, 1573-1578 http://dx.doi.org/10.1136/gut.2005.070896

Walle U. K., Walle T. (1998): Taxol transport by human intestinal epithelial Caco-2 cells. Drug Metab. Dispos. 26, 343-346

Xin H.-W., Schwab M., Klotz U. (2006): Transport studies with 5aminosalicylate. Eur. J. Clin. Pharmacol. 62, 871-875 http://dx.doi.org/10.1007/s00228-006-0182-3

Yoshimura S., Kawano K., Matsumura R., Sugihara N., Furuno K. (2009): Inhibitory effect of flavonoids on the efflux of N-acetyl 5 -aminosalicylic acid intracellularly formed in Caco-2 cells. J. Biomed. Biotechnol. 2009, 467489 
http://dx.doi.org/10.1155/2009/467489

Zhou S. Y., Fleisher D., Pao L. H., Li C., Winward B., Zimmermann E. M. (1999a): Intestinal metabolism and transport of 5-aminosalicylate. Drug Metab. Dispos. 27, 479-485

Zhou S. Y., Piyapolrungroj N., Pao L., Li C., Liu G., Zimmermann E., Fleisher D. (1999b): Regulation of paracellular absorption of cimetidine and 5-aminosalicylate in rat intestine. Pharm. Res. 16, 1781-1785 http://dx.doi.org/10.1023/A:1018974519984

Zídek Z., Kmoníčková E., Kostecká P., Tlaskalova-Hogenová H. (2010): Decisive role of lipopolysaccharide in activating nitric oxide and cytokine production by the probiotic
Escherichia coli strain Nissle 1917. Folia Microbiol. 55, 181-189

http://dx.doi.org/10.1007/s12223-010-0027-4

Zyrek A. A., Cichon Ch., Helms S., Enders C., Sonnenborn U., Schmidt M. A. (2007): Molecular mechanisms underlying the probiotic effects of Escherichia coli Niessle 1917 involve ZO-2 and PKCद. redistribution resulting in tight junction and epithelial barrier repair. Cell. Microbiol. 9, 804-816 http://dx.doi.org/10.1111/j.1462-5822.2006.00836.x

Received: September 24, 2012

Final version accepted: February 11, 2013 